Farum

Sociológico

\section{Forum Sociológico}

Série II

$34 \mid 2019$

Habitação nas áreas urbanas de Lisboa e Porto: Da comunidade aos decisores políticos

\title{
Espaços Nem-nem - Nem Públicos Nem Privados, em Edifícios de Habitação Social de Grande Porte
}

Spaces neither-nor - Neither Public Nor Private, in Large-Scale Social Housing Buildings

\section{Teresa Madeira da Silva}

\section{OpenEdition}

Journals

\section{Edição electrónica}

URL: https://journals.openedition.org/sociologico/4728

DOI: $10.4000 /$ sociologico.4728

ISSN: 2182-7427

\section{Editora}

CICS.NOVA - Centro Interdisciplinar de Ciências Sociais da Universidade Nova de Lisboa

\section{Edição impressa}

Paginação: 31-42

ISSN: 0872-8380

\section{Refêrencia eletrónica}

Teresa Madeira da Silva, «Espaços Nem-nem - Nem Públicos Nem Privados, em Edifícios de Habitação Social de Grande Porte», Forum Sociológico [Online], 34 | 2019, posto online no dia 19 agosto 2019, consultado o 29 março 2022. URL: http://journals.openedition.org/sociologico/4728 ; DOI: https:// doi.org/10.4000/sociologico.4728 


\title{
ESPAÇOS NEM-NEM - NEM PÚBLICOS NEM PRIVADOS EM EDIFÍCIOS DE HABITAÇÃO SOCIAL DE GRANDE PORTE
}

\section{SPACES NEITHER-NOR - NEITHER PUBLIC NOR PRIVATE IN LARGE-SCALE SOCIAL HOUSING BUILDINGS}

Teresa Madeira da Silva

ISCTE-IUL, Instituto Universitário de Lisboa, Escola de Tecnologias e Arquitetura, Departamento de Arquitetura e urbanismo / DINAMIA'CET-IUL

\begin{abstract}
Resumo
A partir do estudo de dois conjuntos de habitação social construídos em Marvila (Lisboa), conhecidos por Zona J e Pantera Cor-de-Rosa, propomos investigar o modo como se organizam e são utilizados os espaços de circulação e acessos em edifícios de grande porte organizados em galeria. Além dos espaços públicos e privados verificámos a existência de espaços semipúblicos, aqui designados de nem-nem, nem públicos nem privados, que correspondem aos espaços de circulação, no interior dos edifícios partilhados por vários lotes: corredores, galerias, halls, passadiços (circulações horizontais), ou escadas, rampas e elevadores (circulações verticais), cuja apropriação é pouco clara. 0 modo como esses espaços se organizam traz consequências positivas e negativas para os seus habitantes. Por um lado, é propício ao estabelecimento de relações de pertença pela apropriação por parte dos seus moradores, por outro, é motivo e área de conflito entre moradores de diferentes lotes, tornando a gestão difícil pela deficiente definição dos limites entre público e privado.
\end{abstract}

Palavras-chave: habitação social, espaços nem-nem, modelos arquitetónicos

\begin{abstract}
Departing from the study of two social housing building sets located in Marvila (Lisbon), called Zona $\mathrm{J}$ and Pantera Cor-de-Rosa (Pink Panther), we propose to investigate how the circulation spaces and accesses are used on gallery organized large buildings. In addition to the public and private spaces, we have confirmed the existence of semi-public areas, here called "neither-nor" - neither public nor private -, correspondents to the circulation spaces within the buildings and shared by several lots: corridors, galleries, halls, walkways (horizontal circulations), or stairs, ramps and elevators (vertical circulation), where the appropriation is unclear. The way these spaces are organized has both positive and negative consequences for its inhabitants. On one hand, it is conducive to the establishment of belonging relations by its inhabitants on the appropriation process, on the other hand, it is conflict motive and arena between residents of different lots, making local building management difficult due to the poor definition of the boundaries between public and private.
\end{abstract}

Keywords: social housing, neither-nor spaces, architectural models

\section{Introdução}

Pretende-se aprofundar o debate sobre o modo de organização e de utilização dos espaços de circulação em dois conjuntos de edifícios de habitação social de grande porte construídos em
Marvila (Lisboa), conhecidos por Zona J (Figura 1), e Pantera Cor-de-Rosa (Figura 2).

Os dois conjuntos, projetados e construídos nas décadas de 70 e 80 do século $X X$, situam-se, respetivamente, no bairro do Condado e no bairro dos Lóios, na zona oriental da cidade. Foram construídos 
Figura $1 \triangleright$ Zona J, bairro do Condado, Marvila, Lisboa

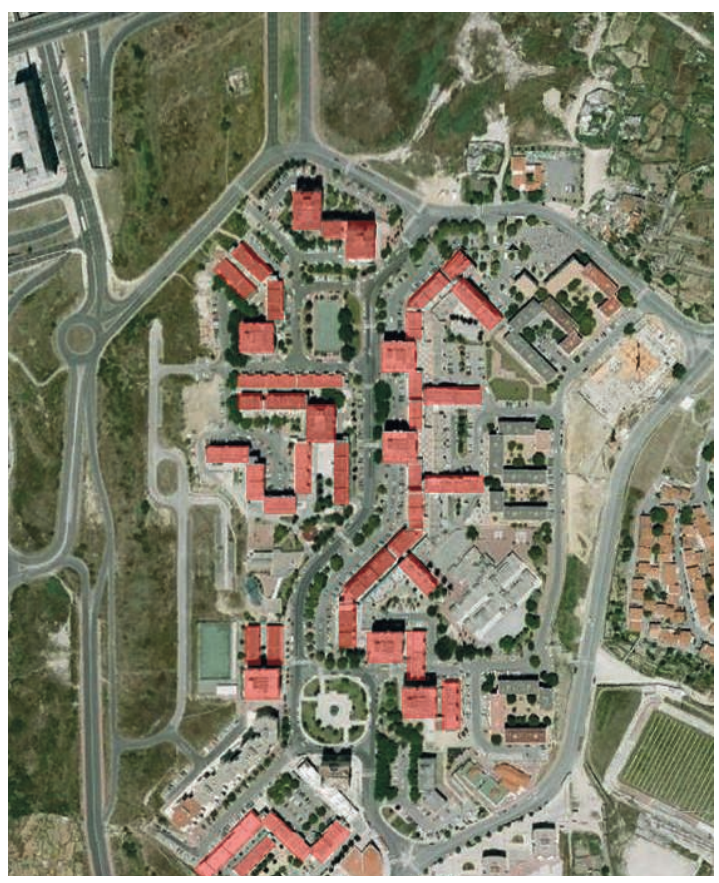

Fonte: Silva, 2011, a partir de fotografia aérea de: https://www.google.pt/maps

após a revolução de abril de 1974 com o intuito de alojar principalmente retornados das ex-colónias e população que vivia em barracas nestas e noutras zonas da cidade. A construção da maioria destes bairros correspondeu à resposta necessária a um problema quantitativo - o défice de habitação que se verificava à época. Decorridos cerca de 40 anos desde a sua construção, estes conjuntos urbanos apresentam apreciáveis níveis de deterioração e indícios de inadequabilidade, proporcionando uma fraca qualidade de vida urbana.

Questionámos o facto de a tipologia urbana, neste caso, edifícios de grande porte, organizados em galeria, onde o acesso às habitações é feito a partir de espaços designados de espaços nem-nem (de nem são públicos nem são privados), por analogia com o termo utilizado para a geração nem-nem ${ }^{1}$, ter reflexos na forma como os seus habitantes utilizam e usufruem esses mesmos espaços.

\section{Definição de conceitos e revisão bibliográfica}

Para aprofundar o debate sobre a questão da organização dos espaços de circulação em edifícios de grande porte em galeria importa estabelecer as diferenças entre alguns conceitos a fim de construir um quadro conceptual que fundamente teoricamente os conceitos utilizados, nomeadamente as conceções de espaço público, privado, semipúblico, espaço comum e espaço nem-nem.
Figura $2 \triangleright$ Pantera Cor-de-Rosa, bairro dos Lóios, Marvila, Lisboa

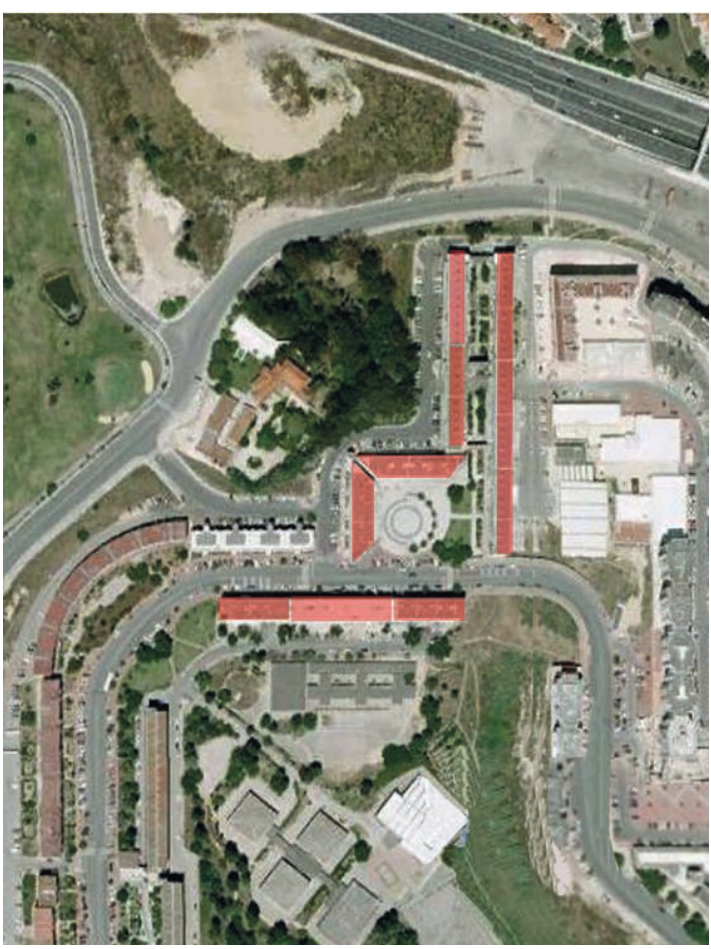

Fonte: Silva, 2011, a partir de fotografia aérea de: https://www.google.pt/maps

Apesar de fazermos uma abordagem a partir da morfologia urbana, ou seja, a partir da forma como se organizam os espaços, consideramos que esta se prende com o "modo de utilização e de comunicação figurativa que constitui a 'arquitetura da cidade'" (Lamas, s. d., p. 44). Assim, na linha de Hertzberg (1996), consideramos espaço público a "área acessível a todos a qualquer momento; [sendo que] a responsabilidade pela sua manutenção é assumida coletivamente" (Hertzberger, 1996, p. 12). Por outro lado, espaço privado "é uma área cujo acesso é determinado por um pequeno grupo ou por uma pessoa, que tem a responsabilidade de mantê-la" (Hertzberger, 1996, p. 12). Em contexto urbano, o espaço público é normalmente o espaço que envolve os edifícios, sendo que as vias são o espaço público predominante da imagem urbana de uma cidade (Lynch, 1988, p. 58). Por oposição, o espaço privado situa-se normalmente no interior dos edifícios. Para Hertzberger, porém, a oposição entre o público e o privado é excessiva, uma vez que as pessoas e os grupos estão sempre "em inter-relação e compromisso mútuo" (Hertzberger, 1996, p. 12). Para este autor, as demarcações territoriais são sempre relativas, em função dos espaços com os quais se relacionam. "Às vezes o grau de acesso é uma questão de legislação, mas, em geral, é 
exclusivamente uma questão de convenção, que é respeitada por todos" (Hertzberger, 1996, p. 15). No caso dos edifícios em estudo, é visível a indefinição entre público e privado, uma vez que existe um conjunto de espaços comuns, ou seja, partiIhados por habitantes de diferentes lotes, que não são privados, porque não são afetos diretamente a qualquer morador ou proprietário, mas também não são públicos, porque pertencem aos edifícios e, por isso, não são claramente acessíveis a todos. Esses espaços - corredores, galerias, halls, passadiços (circulações horizontais), ou escadas, rampas e elevadores (circulações verticais) - são considerados semipúblicos, porque, apesar de pertencerem aos edifícios, não são delimitados em relação ao espaço público. Dada a sua indefinição, estes espaços são aqui designados de espaços nem-nem.

Destacamos, igualmente, alguma bibliografia de referência para fundamentar a análise dos casos de estudo. As obras de Jane Jacobs (2007) e de Ferreira dos Santos et al. (1985) estudam o funcionamento das cidades e as relações entre tipologia do espaço público e segurança, sendo estes autores críticos do planeamento urbano moderno por este não valorizar a escala humana e a função social da cidade. Para estes autores, a ausência de diversidade implícita no planeamento racionalista de tradição modernista cria problemas de insegurança nas populações que neles habitam. Também o dossier temático "as pessoas não são coisas que se ponham em gavetas", coordenado por Ferreira, Guerra \& Freitas (1994), serviu de referência porque questiona, "do ponto de vista social, os efeitos perversos da concentração espacial de uma população socialmente homogénea" (Guerra, 1994 , p. 11). Segundo os autores, no caso de Lisboa, esses efeitos "provocaram um crescimento exponencial de comportamentos desviantes e de estigmas socias que desencadearam, por sua vez, respostas violentas e um clima de insegurança..." (Guerra, 1994, p. 11). Teresa Valsassina Heitor trata da vulnerabilidade dos conjuntos urbanos de habitação social em Chelas, pressupondo que o seu "o padrão espacial (...) pode contribuir para tornar o espaço construído vulnerável a ações de negligência e a comportamentos transgressivos por parte da população" (Heitor, 2001, p. 3). Com um ponto de vista diferente, Bristol (1991), a propósito do conjunto habitacional Pruitt-Igoe, refere que é um mito responsabilizar o projeto arquitetónico de Pruitt-Igoe pelo seu fracasso, uma vez que toda a história desse fracasso envolve questões económicas e condições políticas. Para a autora, esta associação só serve para legitimar a profissão do arquiteto por tornar implícito que problemas sociais se resolvem através do projeto arquitetónico.

Para a realização da análise e do diagnóstico dos dois conjuntos urbanos, vários estudos serviram de referência, tais como: a "Operação Cova da Moura", (Malheiros, Vasconcelos \& Alves, 2006), a "Operação Vale da Amoreira" (2006), e a "Operação Lagarteiro" (Marques, 2006). Estes estudos apoiaram a metodologia adotada no estudo dos dois conjuntos habitacionais. Contributos para o Plano Estratégico de Habitação 2008/2013 - Documento Políticas Urbanas, elaborado pelo CET/ISCTE, ajudou-nos a contextualizar os bairros nas políticas da habitação em Portugal (Guerra, Pereira, Fernandes, Botelho \& Marques, 2008).

\section{Enquadramento e análise morfológica dos edifícios}

Os dois bairros de habitação social foram objeto de um Estudo de Avaliação e Diagnóstico das Necessidades de Intervenção no edificado realizado em 2011 (Silva, 2011)2. O objetivo do estudo era dotar o Programa Viver Marvila de um documento de suporte às intervenções no edificado, tendo em consideração as problemáticas de cada lote ou conjunto de lotes, apresentar propostas técnicas e financeiras sustentáveis e otimizar o bom desempenho funcional das construções, assegurando a durabilidade de futuras intervenções. Tendo por base o estudo, cujo foco é a intervenção no edificado, iremos tratar questões relacionadas com os aspetos morfológico e de organização dos espaços de circulação e acessos nos dois conjuntos, centrando as nossas questões na área disciplinar da arquitetura.

Bairro do Condado (Zona J). Propriedade da Câmara Municipal de Lisboa, os edifícios, projetados pelo arquiteto Tomás Taveira, foram construídos na década de 80 e desde 2003 até agora são geridos pela GEBALIS (Empresa de Gestão do Arrendamento da Habitação Municipal de Lisboa, EM, SA).

Em termos de composição urbana, o conjunto principal foi construído a partir de dois grupos de lotes em banda paralelos, resultando, desse alinhamento, um espaço-corredor de carácter público, com cerca de 6 metros de largura, 300 metros de comprimento e delimitado por edifícios com alturas entre 3 e 13 pisos. Este espaço-corredor foi pensado inicialmente como espaço de estar e de encontro dos moradores, no entanto, depois de ocupado, transformou-se numa das zonas mais inseguras de Chelas, ficando conhecido como o corredor da morte, por nele se verificarem muitos atos de violência e criminalidade ${ }^{3}$. Essencialmente constituídos por habitação nos pisos superiores, estes edifícios têm nos pisos térreos comércio, serviços, equipamentos e arrecadações, sendo que a maioria está fechada e tem frentes cegas para o corredor central e para as ruas confinantes (Figuras 3 e 4). 
Figura $3 \triangleright$ Piso térreo para o corredor central. Bairro do Condado, Zona J, Marvila, Lisboa

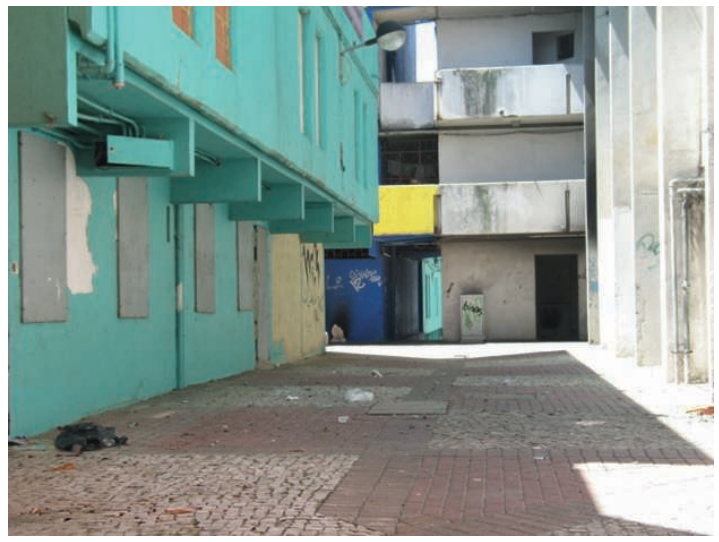

Fonte: Silva, 2011

Figura $4 D$ Piso térreo para a rua. Bairro do Condado, Zona J, Marvila, Lisboa

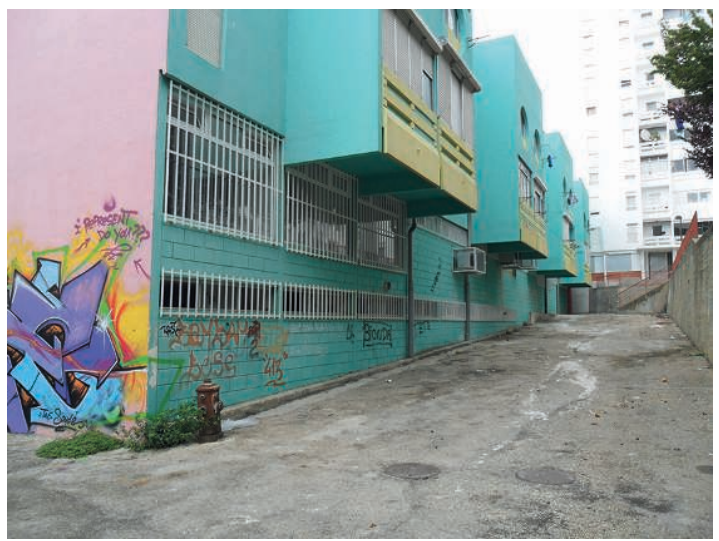

Fonte: Silva, 2011

Os edifícios apresentam dois tipos de estrutura: um, do tipo linear, que se desenvolve numa sequência de galerias, com fogos tipo dúplex, de 3 a 9 pisos, e onde o acesso aos lotes se faz a partir da rua através de módulos verticais (escadas e elevadores, ou só escadas), que acedem às galerias e estas às entradas dos fogos (Figura 5 ).

Outro, do tipo torre, com 13 pisos e 6 fogos por piso, perfazendo 71 fogos cada. Cada piso é composto por 2 T2 e 4 T3 que se organizam à volta de uma galeria aberta para um saguão central que percorre todos os pisos, acentuando a verticalidade do conjunto. Para a galeria abrem-se as entradas dos fogos e os acessos verticais (as caixas de escadas, 2 por torre, e os elevadores, 3 por torre) (Figura 6).

Bairro dos Lóios (Pantera Cor-de-Rosa). Os edifícios do bairro dos Lóios, projetados pelos arquitetos Gonçalo Byrne e António Reis Cabrita, têm como atuais proprietários o IHRU e alguns privados (moradores que adquiram as habitações onde residiam). Os edifícios de 4 a 8 pisos organizam-se em galerias: dois corpos paralelos criam um espaço público com alguma privacidade (Figura 7), outros organizam-se formando uma praça quadrada (a Praça Raul Lino), onde a atividade comercial e de serviços aí instalada cria uma centralidade no conjunto do bairro (Figura 8).

Os edifícios são constituídos por unidades de habitação (fogos simples ou dúplex) nos pisos superiores, e por comércio, serviços ou arrecadações (algumas delas encerradas e apropriadas para uso habitacional) nos pisos térreos. As pontes entre blocos, elementos característicos deste conjunto, têm como objetivo reduzir o número de acessos verticais (escadas e elevadores).

\section{Metodologia do estudo}

Em termos metodológicos, o estudo realizou-se a partir de três fases de trabalho: o levantamento do edificado, o diagnóstico das necessidades de intervenção e os cenários de intervenção ${ }^{4}$.

O levantamento teve, na sua origem, a recolha e o tratamento da informação disponível. Num pri-

Figura $5 \triangleright$ Estrutura linear (lotes em galeria). Bairro do Condado, Zona J, Marvila, Lisboa

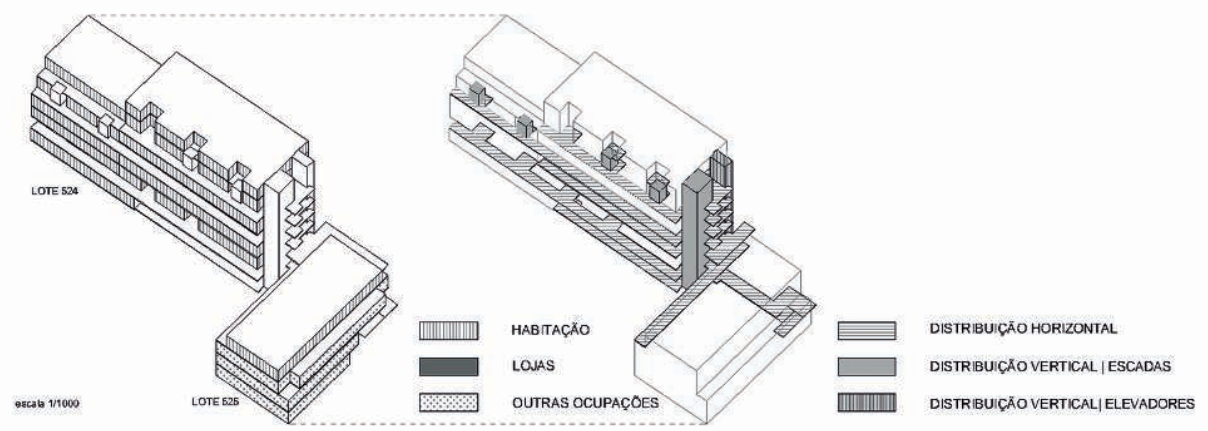

Fonte: Silva, 2011 
Figura $6 \triangleright$ Estrutura em torre. Bairro do Condado, Zona J, Marvila, Lisboa
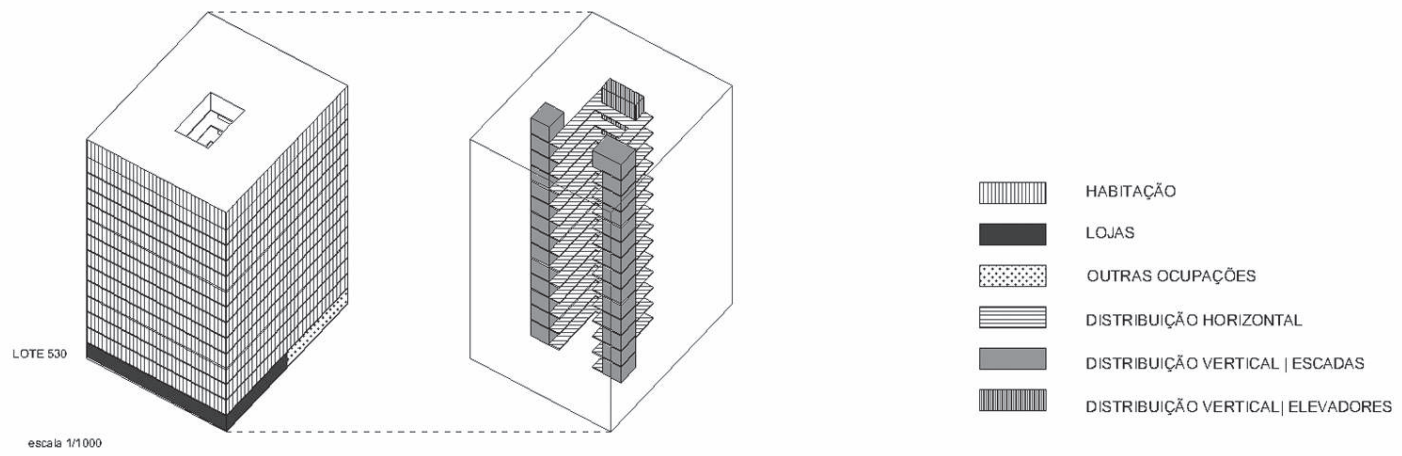

Fonte: Silva, 2011

Figura $7 \triangleright$ Estrutura linear (lotes em galeria). Bairro dos Lóios, Pantera Cor-de-Rosa, Marvila, Lisboa

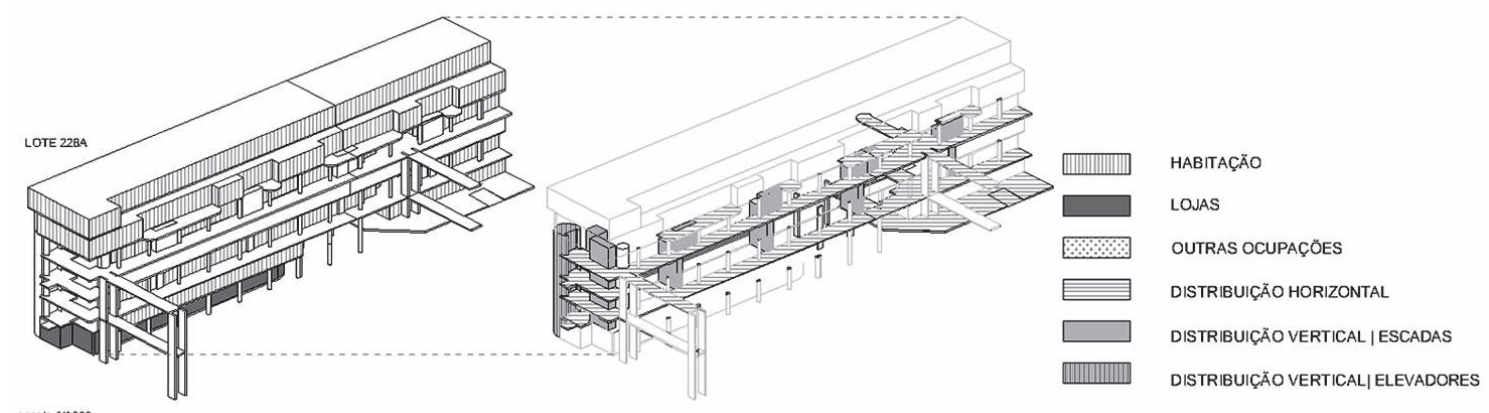

Fonte: Silva, 2011

Figura 8. Estrutura da praça. Bairro dos Lóios, Pantera Cor-de-Rosa, Marvila, Lisboa

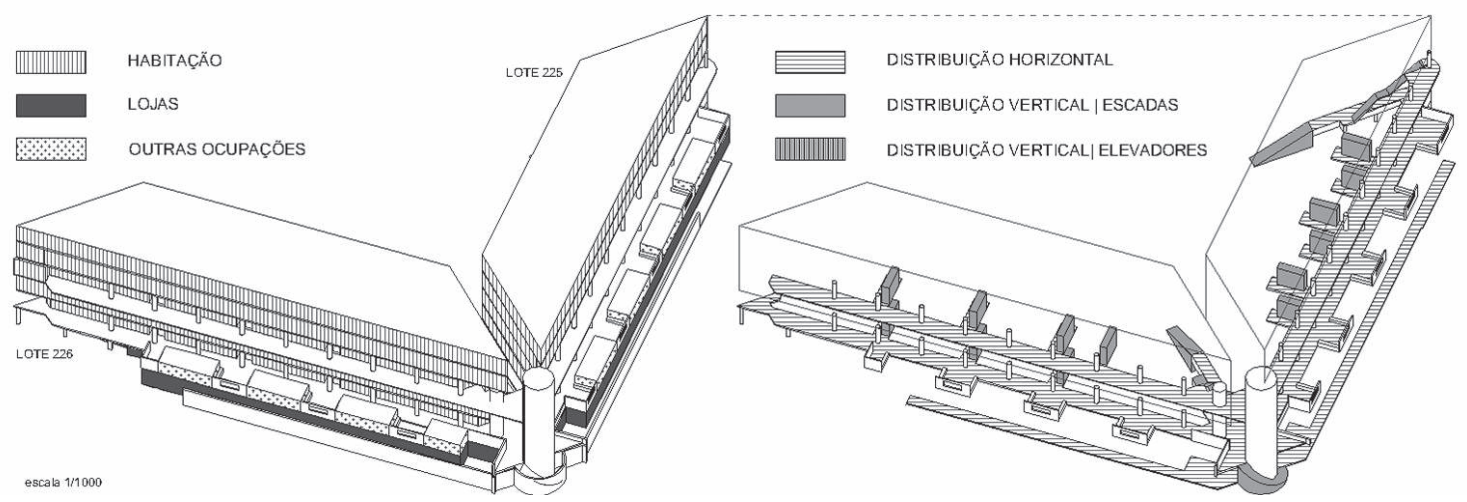

Fonte: Silva, 2011

meiro momento, os projetos originais serviram para atualizar a informação recolhida. Em colaboração com o gabinete Viver Marvila acedemos aos originais dos projetos de arquitetura: em papel (da Zona J) e, em formato digital (da Pantera Cor-de-Rosa), cedido pelo Arquivo do Forte de Sacavém. Esta documen- tação serviu para a produção de peças gráficas que subsidiaram todo o trabalho de campo. Nesta fase, realizaram-se reuniões alargadas com os serviços do IHRU e com a sua equipa técnica do Programa Viver Marvila, localizada em Chelas. Procedeu-se à recolha de dados, em relação ao regime de pro- 
priedade, às atividades, ao tipo de ocupação, às associações, etc. Realizaram-se igualmente reuniões com diversos agentes e parceiros locais no sentido de perceber o tipo de vivência do bairro. Na fase de levantamento produziram-se peças gráficas de todos os edifícios por piso (plantas e cortes) em formato digital (Figura 9).

Figura $9 \triangleright$ Levantamento. Planta do piso 0. Bairro dos Lóios, Pantera Cor-de-Rosa, Marvila, Lisboa

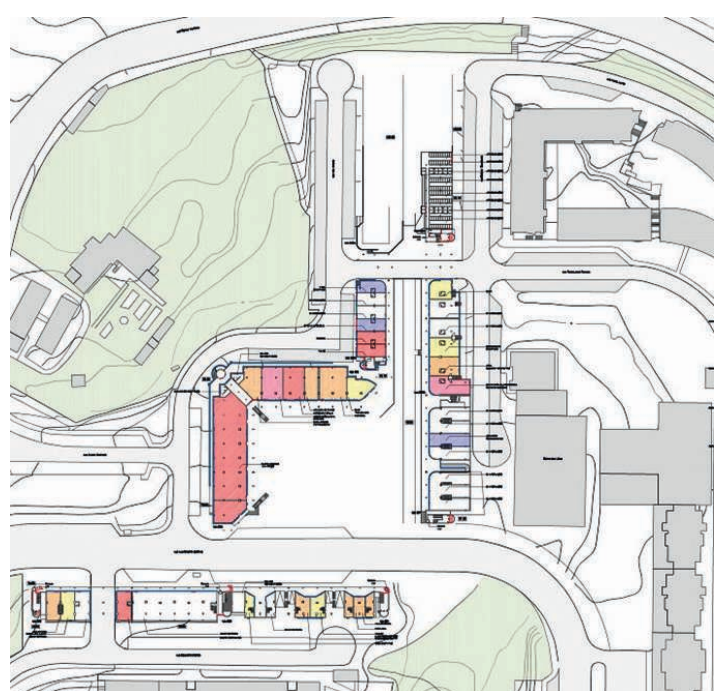

Fonte: Silva, 2011

O diagnóstico consistiu na realização de fichas, onde foram registadas as informações complementares ao levantamento e à descrição dos edifícios. Dado que o acesso aos lotes se faz, maioritariamente, através de serventias partilhadas, designámos por unidades funcionais os lotes, ou conjuntos de lotes, que dependem dos mesmos acessos, ou seja, parti-
Iham as mesmas escadas, percursos de circulação, elevadores, etc. (Figura 10).

Encontramos 22 unidades funcionais no bairro do Condado (Figura 11).

E 9 unidades funcionais no Bairro dos Lóios (Figura 12).

Figura $11 \triangleright$ Planta de localização e delimitação das unidades funcionais. Bairro do Condado, Zona J, Marvila, Lisboa

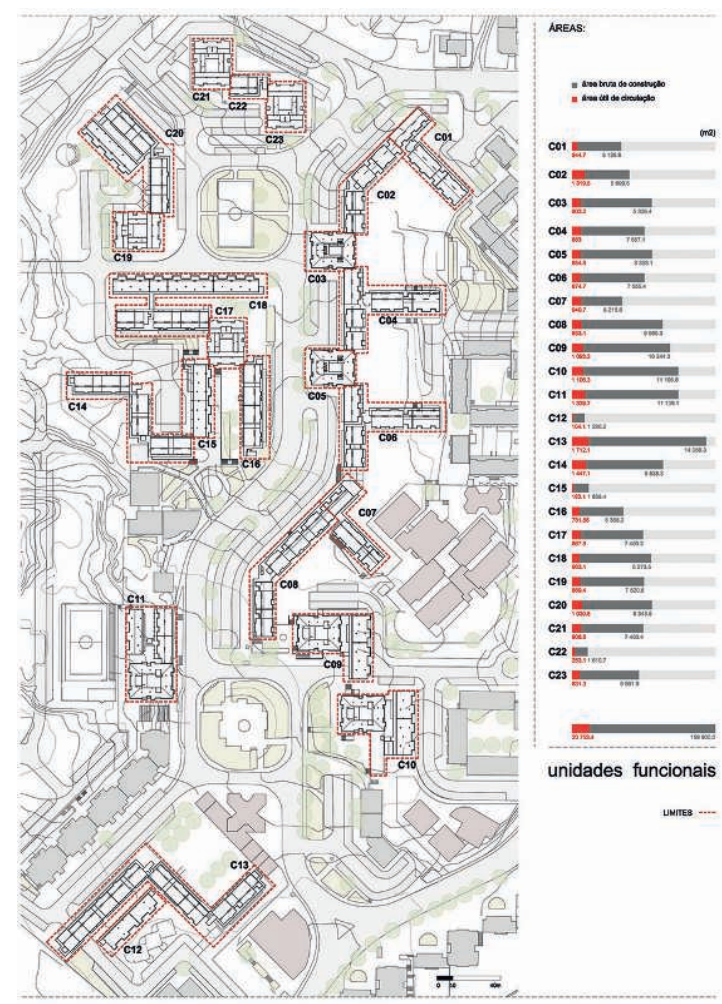

Fonte: Silva, 2011, cf. https://www.google.pt/maps

Figura $10 \triangleright$ Exemplo de uma unidade funcional com três lotes dependendo da mesma caixa de escada e elevadores. Bairro do Condado, Zona J, Marvila, Lisboa

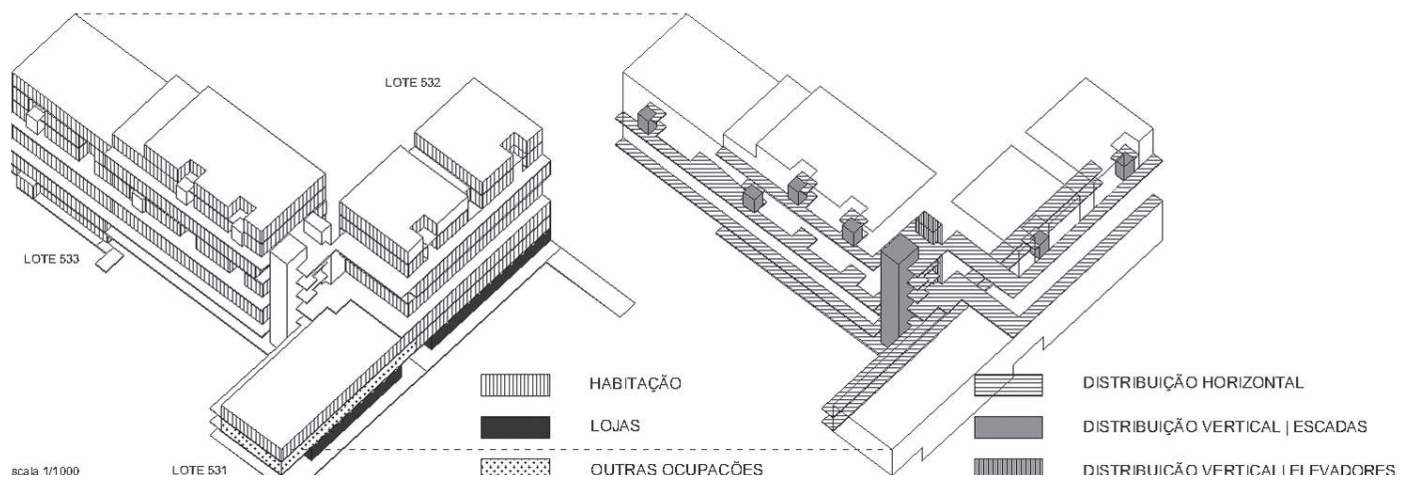

Fonte: Silva, 2011 
Figura $12 \triangleright$ Planta de localização e delimitação das unidades funcionais. Bairro dos Lóios, Pantera Cor-de-Rosa, Marvila, Lisboa

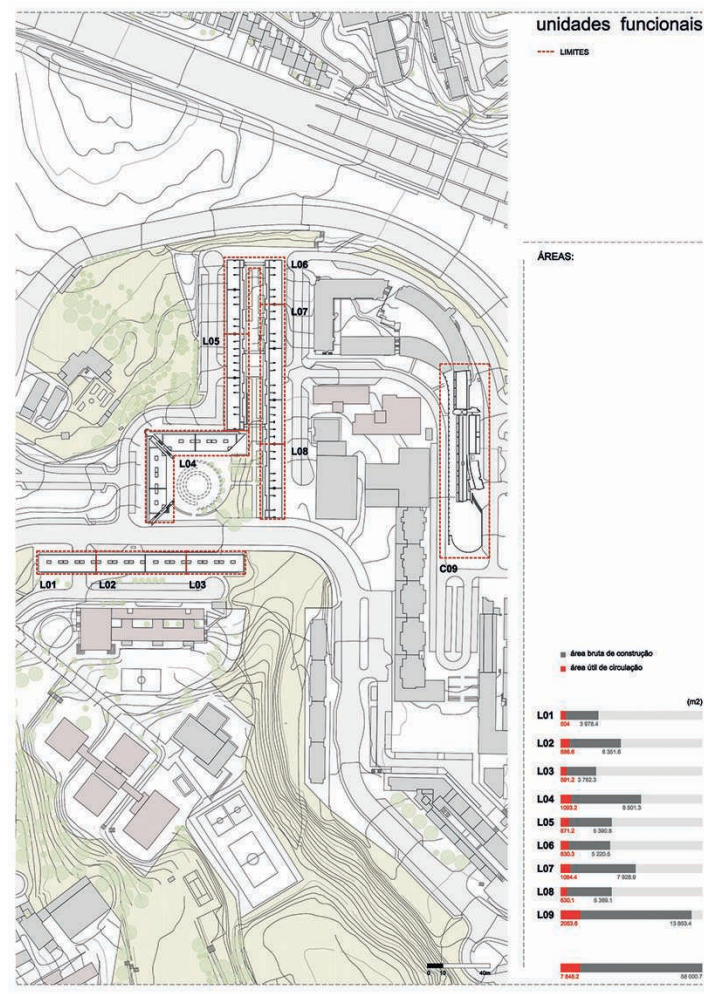

Fonte: Silva, 2011

As fichas de diagnóstico informam-nos acerca da localização das unidades funcionais, do número de lotes, do número de pisos, do número de circulações verticais, dos valores de proximidade, das tipologias, dos acessos, dos espaços intermédios (acessos, halls, pátios, galerias, corredores, terraços, etc.), do tipo de usos (habitação, comércio, serviços, restauração, lazer, etc.), da composição construtiva, das patologias estruturais, da acessibilidade às redes, da situação geográfica, da forma de assentamento no terreno, do tipo de proteção solar dos vãos, do aproveitamento passivo de energia, da segurança contra incêndios, da gestão dos edifícios e da produtividade (Figuras 13 e 14).

Em todas as fases do trabalho, realizaram-se visitas aos bairros e envolvente próxima, com as equipas de técnicos do IHRU e do programa Viver Marvila.

\section{Discussão}

A partir do diagnóstico, dividimos a nossa discussão em três pontos: o primeiro é sobre a relação bairro/cidade, o segundo sobre a relação edifício/ /espaço público, e o terceiro sobre os espaços nem-nem (espaços comuns no interior dos edifícios).
Sobre a relação bairro/cidade. Observámos que estes bairros servem apenas os seus habitantes e utilizadores, e raramente são atravessados por terceiros, constituindo-se como um impasse social. Esta não transversalidade urbana/social/viária reforça a noção de que estes bairros são "ilha urbana", ou aquilo que Jane Jacobs designa como "zona de fronteira de uso único" (Jacobs, 2007, p. 287).

Encontrámos um desenho de implantação dos conjuntos residenciais com uma leitura clara do território, empregando os princípios do modernismo (Figura 15), no entanto, esta é adversa à ideia de continuidade com a envolvente rural (e de lazer), que acontece de forma desorganizada, por apropriação de baldios, não tendo em vista os interesses dos residentes.

Sobre a relação edifício/espaço público. Verificámos que nestes edifícios os pisos térreos (à exceção das entradas dos lotes), na sua maioria, se encontram encerrados porque ou são habitações, ou arrecadações, ou estão abandonados, constituindo barreiras entre a rua e o edifício, dificultando o seu bom funcionamento. Também encontrámos vários elementos construídos (muros, escadas, paredes cegas, etc.), que dificultam a leitura e o controlo do espaço público por não terem um desenho claro (Figuras 3 e 4).

Sobre os espaços nem-nem. Observámos que estes espaços são o suporte físico de acesso às habitações e assumem especial relevância, porque organizam o edifício. Como espaços comuns, é aqui que se dá o primeiro contacto entre os moradores e os visitantes, é onde se verifica o estabelecimento de relações de vizinhança, e o estabelecimento de relações de pertença entre a rua e o espaço privado da habitação. A separação entre a casa (espaço privado) e a rua (o espaço público) é feita através destes espaços aqui designados de nem-nem (nem são públicos nem são privados), que intermedeiam o domínio público e o domínio privado onde vários lotes partilham os mesmos percursos de circulação, as mesmas escadas, galerias, elevadores, acessos, etc. Estes espaços de transição são espaços de uso coletivo e livre acessibilidade, existem no interior dos edifícios e servem para promover a transição entre os domínios público e privado (Heitor, 2001). Dos 43 lotes estudados do Condado e dos 9 lotes estudados nos Lóios, apenas 11 e 5, respetivamente, funcionam de forma isolada, sendo que os restantes partilham núcleos de acessos (escadas, galerias e elevadores). É de notar que estes espaços constituem percursos de fuga em caso de incêndio, apesar de não terem as dimensões das unidades de passagem desejáveis, nem as situações de impasse cumprirem as distâncias desejáveis às circulações verticais (Figura 16). O registo médio de distância máxima até às circulações verticais, em situação de impasse, no Condado é de 44,2 m 
Figura $13 \triangleright$ Ficha de diagnóstico da unidade funcional C08. Bairro do Condado, Zona J, Marvila, Lisboa
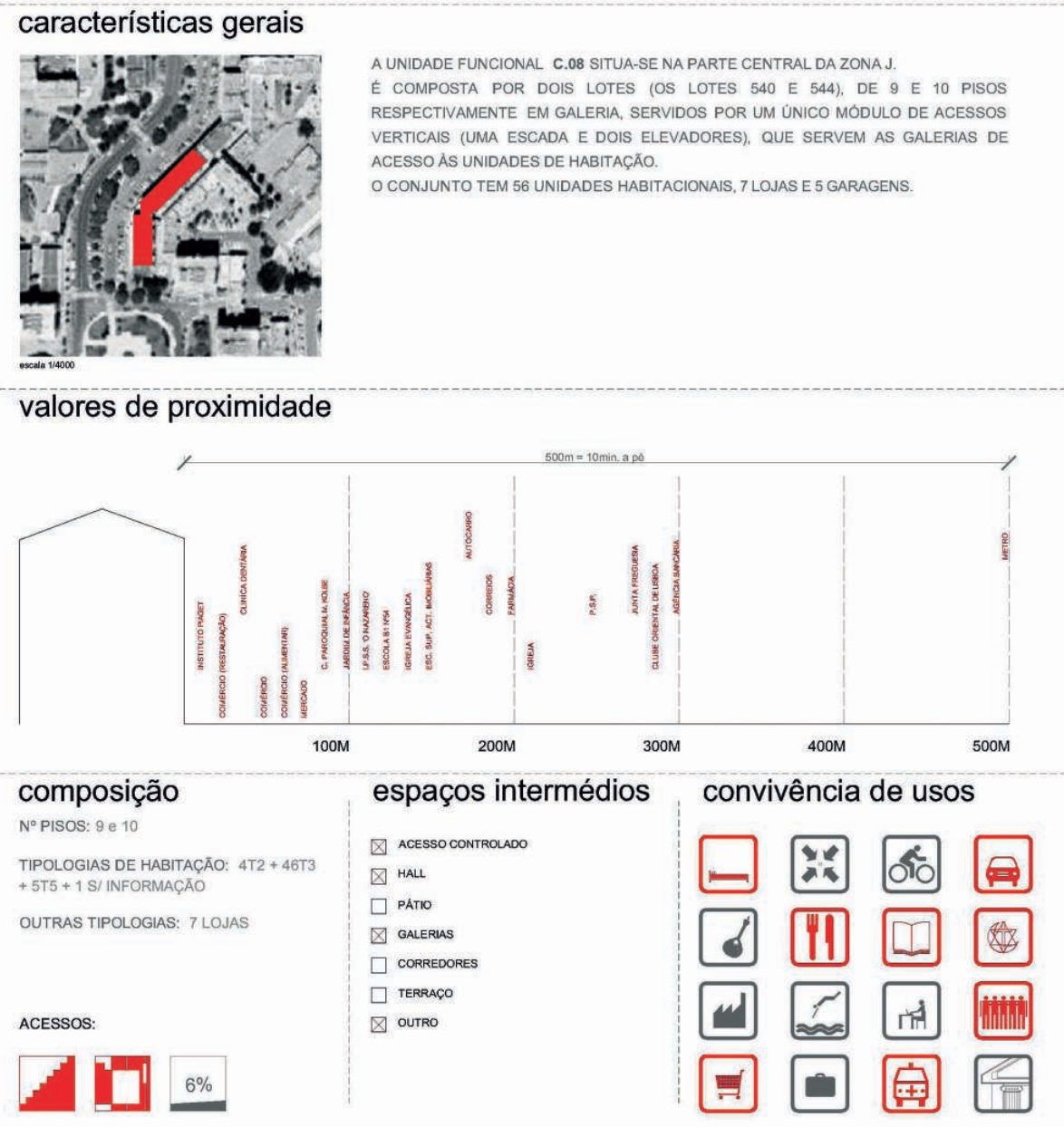

Fonte: Silva, 2011

e nos Lóios de 53,5 m. A distância máxima até à circulação vertical registada no Condado é $88,9 \mathrm{~m}$ e nos Lóios de $81,7 \mathrm{~m}^{5}$.

Nas entradas, o mau funcionamento dos trincos e a ausência de campainhas levam a que a "porta da rua" esteja por regra aberta, tornando o espaço de hall um contínuo espaço de ninguém que só parece acabar ou na porta de casa, ou em formas espontâneas de controlo, através da colocação de portões e grades.

\section{Conclusão}

Os condicionalismos do território, consequência da topografia e do desenho do traçado, manifestam- -se na dispersão e no isolamento dos conjuntos habitacionais no território que, consequentemente, originam uma fraca relação entre eles. Este facto propicia, por um lado, a exclusão social e o isolamento dos seus habitantes em relação ao resto da cidade, e, por outro, a dificuldade de aceder aos serviços e equipamentos fora do bairro.

O facto de não existir uma hierarquia definida entre espaços públicos, semipúblicos e privados, assim como o facto de se verificar uma indefinição entre esses espaços (públicos e privados), conduz à existência de espaços anónimos ou impessoais, cuja utilização é pouco clara, dificultando a sua apropriação de forma adequada pela população que neles habita. Esses espaços anónimos são por 
Figura $14 \triangleright$ Ficha de diagnóstico da unidade funcional C08 (continuação). Bairro do Condado, Zona J, Marvila, Lisboa

\section{C.08}

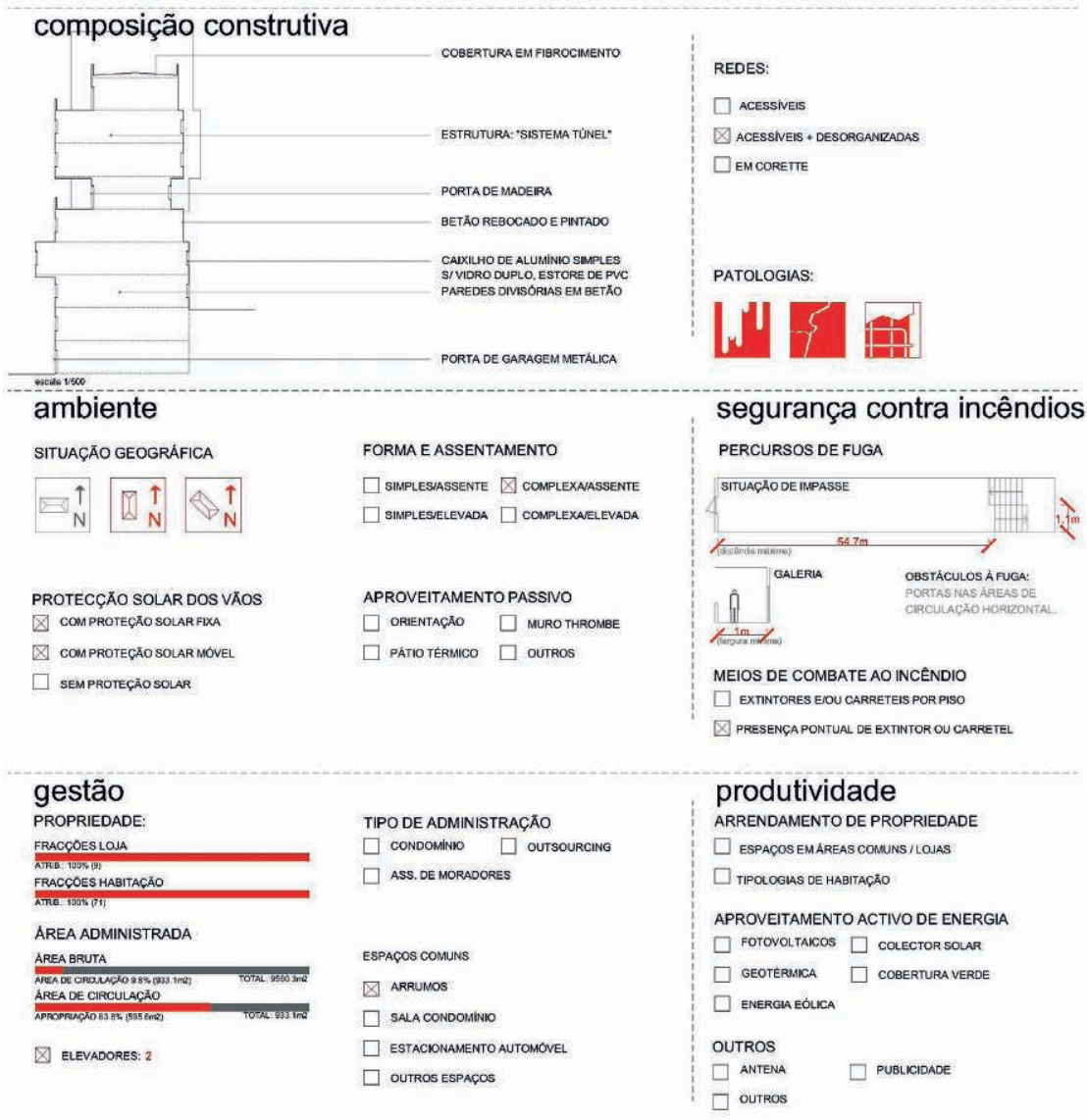

Fonte: Silva, 2011

Figura $15 \triangleright$ Relação bairro/cidade. Bairro do Condado e bairro dos Lóios, Marvila, Lisboa
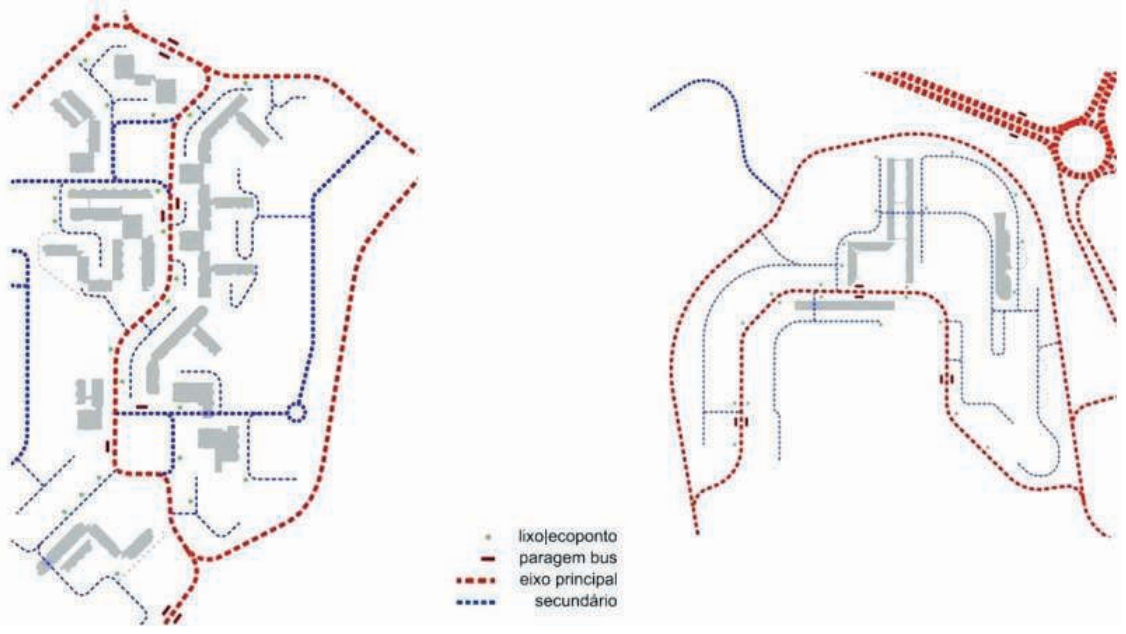

Fonte: Silva, 2011 
Figura $16 \triangleright$ Indicação dos espaços de percurso de fuga. Bairro do Condado, Zona J, Marvila, Lisboa

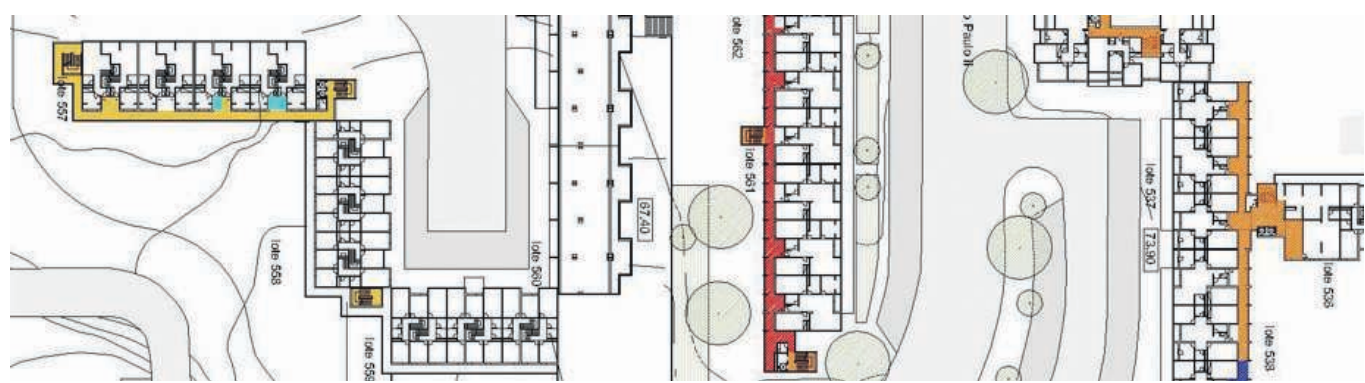

Fonte: Silva, 2011

Figuras 17 e $18 \triangleright$ Controlos do espaço nas galerias. Bairro do Condado, Zona J, e bairro dos Lóios, Pantera Cor-de-Rosa, Marvila, Lisboa
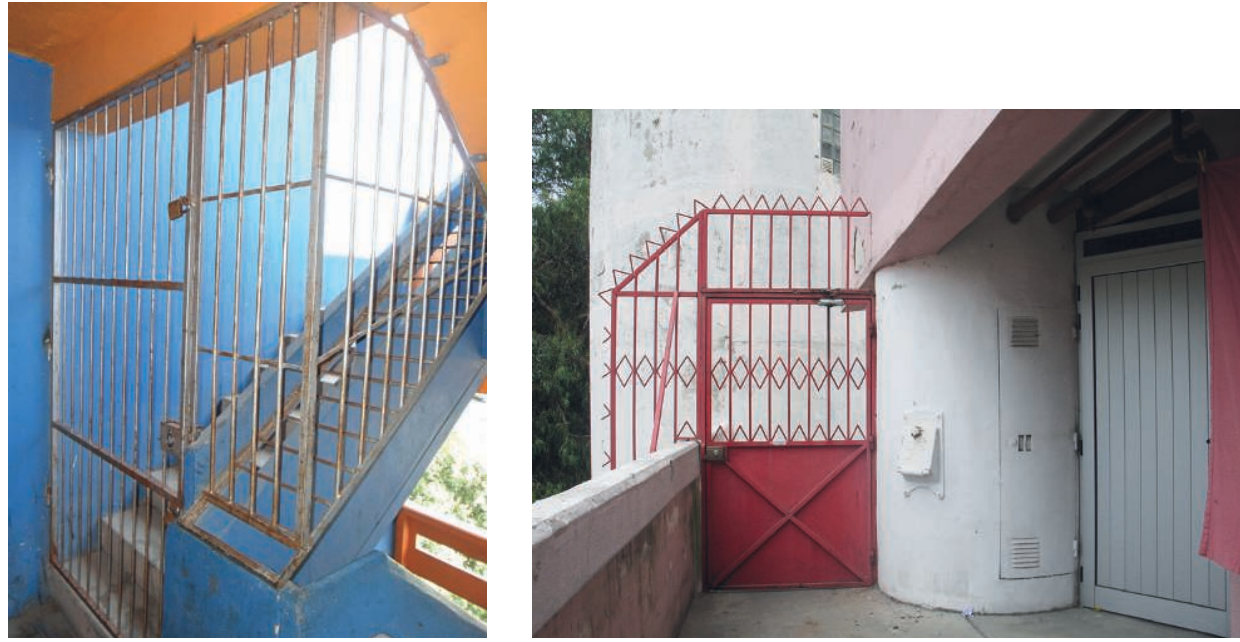

Fonte: Silva, 2011

Figuras 19 e $20 \triangleright$ Utilização das galerias. Bairro do Condado, Zona J, Marvila, Lisboa
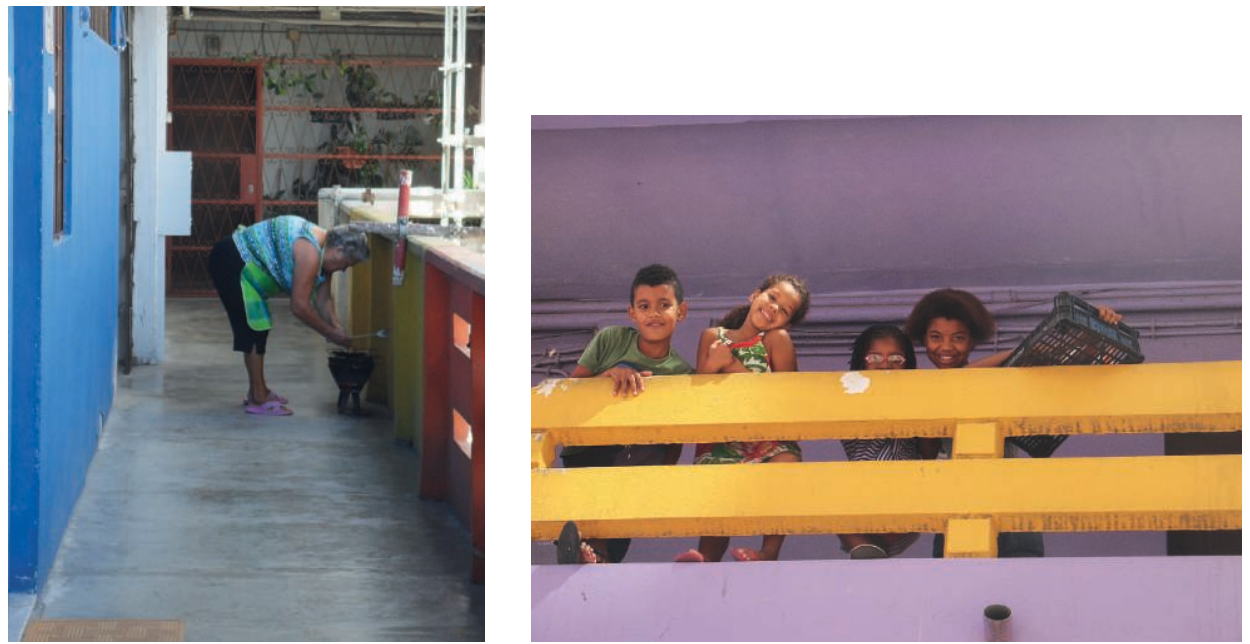

Fonte: Silva, 2011 
isso abandonados, entrando num avançado estado de degradação e deterioração, ou apropriados por vezes de forma ilegal. Assim, a existência de espaços de transição, aqui designados de nem-nem por não terem um carácter nem público nem privado e por serem partilhados entre habitantes de diferentes lotes, traz consequências positivas e negativas para os seus habitantes. Se, por um lado, é propício ao estabelecimento de relações de pertença pela apropriação por parte dos seus moradores, é também motivo e área de conflito entre moradores de diferentes lotes. A apropriação desses espaços comuns de forma desadequada, como seja, encerrando as passagens no interior dos conjuntos edificados, traz situações de difícil gestão como o corte dos percursos de fuga em caso de incêndio e/ou catástrofe, a difícil administração das redes de infraestruturas (água, eletricidade, gás, etc.), a multiplicação de obstáculos às pessoas com mobilidade reduzida e a apropriação ilegal das áreas comuns. A gestão destes conjuntos torna-se difícil, devido à deficiente definição dos limites dos lotes, não permitindo o convencional funcionamento e gestão lote a lote, uma vez que esses espaços não pertencem a um lote, mas a um conjunto de lotes.

\section{Notas}

1 Designámos "espaços nem-nem" que, nem são públicos nem são privados, por analogia com o termo "nem-nem" (de "nem trabalha, nem estuda") aceite para designar a população jovem fora do mercado de trabalho e de instituições educacionais. (Fonte: https://pt.wikipedia. org/wiki/Nem-nem).

2 O estudo foi realizado por uma equipa do ISCTE-IUL, Instituto Universitário de Lisboa, em 2011, tendo sido a equipa selecionada a partir de um concurso por convite promovido pelo IHRU (Instituto de Habitação e Reabilitação Urbana). Equipa: Arquitetura: Teresa Madeira da Silva, Pedro Marques Alves, Miguel Vasconcelos Magalhães, Maria João Oliveira. Colaborador: Samuel Dias. Consultores: Pedro Viana Botelho e Pedro Mendes. Fundações e Estruturas: Fernando Rodrigues. Gestão Energética: Vasco Moreira Rato. Redes e Segurança Integrada: Joaquim Nogueira. Economia, Gestão Urbana e Gestão do Património: Pedro Costa. Coordenação: Teresa Madeira da Silva.

3 Atualmente esse corredor já não existe, porque seis lotes foram demolidos, permitindo que o mesmo se tornasse mais permeável, acessível, visível da rua e, por isso, mais seguro.

4 Não iremos mencionar os cenários de intervenção propostos no estudo por considerarmos que não cabem no âmbito deste artigo.

5 Note-se que o Decreto-Lei n. ${ }^{\circ}$ 220/2008, de 12 de novembro, que aprovou o regime jurídico de segurança contra incêndio, determina que, no caso de edifícios deste tipo, a distância máxima a percorrer nos locais de permanência em edifícios até ser atingida a saída mais próxima, para o exterior ou para uma via de evacuação protegida, deve ser de $15 \mathrm{~m}$ nos pontos em impasse.

\section{Referências bibliográficas}

Bristol, K. (1991). The Pruitt-Igoe Myth. Journal of Architectural Education, 44(3), 163-171.

Cabrita, A. R. (1981). Conjunto habitacional em Chelas: Zona 2. Revista Arquitectura, 4(140), 19-29.

Decreto-Lei n. 0 220/2008 de 12 de novembro. Diário da República n.o 250/2008 - Série I. Lisboa: Ministério da Administração Interna

Ferreira, A. F., Guerra, I., \& Freitas, M. J. (Coords.) (1994). Dossier "As pessoas não são coisas que se ponham em gavetas". Sociedade e Território, 20.

Guerra, I. (1994). As pessoas não são coisas que se ponham em gavetas. Sociedade e Território, 20, 11-16.

Guerra, I., Pereira, S. M., Fernandes, M., Botelho, P., \& Marques, P. (2008). Contributos para o Plano Estratégico de Habitação 2008/2013 - Documento Políticas Urbanas. Lisboa: CET/ISCTE. Retirado de http://habitacao.cm-lisboa.pt/documentos/1234 211200I5eGS7kj9Fq51IF7.pdf

Heitor, T. V. (2001). A Vulnerabilidade do Espaço em Chelas. Uma Abordagem Sintáctica. Lisboa: FCG e FCT.

Heitor, T. v. (s. d.). Olivais e Chelas: Operações urbanísticas de grande escala. Acessível em: https: // www.academia.edu/30782326/Olivais_e Chelas Opera\%C3\%A7\%C3\%B5es_Urban\%C3\%ADsticas_ De_Grande_Escala

Hertzberger, H. (1996). Lições de Arquitetura. São Paulo: Martins Fontes.

IHRU (s. d.). Portal da Habitação. Acessível em: http://www.portaldahabitacao.pt/pt/portal/ glossario.

Iniciativa Bairros Críticos, Operação Vale da Amoreira, Diagnóstico (2006). Vale da Amoreira: GAT.

Jacobs, J. (2007). Morte e Vida de Grandes Cidades. São Paulo: Martins Fontes.

Lamas, J. R. G. (s. d.). Morfologia Urbana e Desenho da Cidade. Lisboa: Fundação Calouste Gulbenkian - Junta Nacional de Investigação Científica e Tecnológica.

Lynch, K. (1988). A Imagem da Cidade. Lisboa: Edições 70 .

Malheiros, J., Vasconcelos, L., \& Alves, F. S. (Coords.) (2006). Operação Cova da Moura, Iniciativa Operação de Qualificação e inserção Urbana em Bairros Críticos, Volume I - Diagnóstico, Lisboa.

Marques, T. S. (Coord.) (s. d.). Operação Lagarteiro. Lagarteiro - Uma intervenção alicerçada na participação. Lisboa.

Montaner, J. M., \& Martinez, Z. M. (2006). Habitar el Presente. Vivienda en España: Sociedad, Ciudad, Tecnología y Recursos. Madrid: Ministerio de Vivienda.

Monteys, X., \& Fuertes, P. (2001). Casa collage: un ensayo sobre la arquitectura de la casa. Barcelona: Editorial Gustavo Gili, SL. 
Pereira, L. V., Gago, M. A. C., \& Lopes, M. J. (1984). Inquérito à Habitação Urbana. Lisboa: LNEC.

Santos, C. N. F. dos, \& Vogel, A. (1985). Quando a rua vira casa: A apropriação de espaços de uso coletivo em um centro de bairro. São Paulo: Projeto.

Silva, T. M. da (Coord.) (2011). Relatório Final. Estudo de Avaliação e Diagnóstico das Necessidades de Intervenção em Edifícios nos Bairros do Condado e dos Lóios em Marvila. Lisboa: ISCTE-IUL.
Silva, T. M. da, Alves, P. M., Magalhães M. V., \& Oliveira, M. J. (2011a). Recuperação do Património Recente: Dois Bairros de Intervenção Prioritária na Periferia de Lisboa. In Atas da Conferência Internacional - Portugal entre desassossegos e desafios. Coimbra: CES, Centro de Estudos Sociais da Universidade de Coimbra.

Silva, T. M. da, Alves, P. M., Magalhães M. V., \& Oliveira, M. J., (2011b). Edifícios de Habitação Social: Diagnóstico e Cenários de Intervenção. CIDADES, Comunidades e Territórios, 22, 82-98.

Recebido a 31/10/2018. Aceite para publicação a 26/02/2019

Teresa Madeira da Silva (teresa.madeira@iscte-iul.pt). Departamento de Arquitetura e Urbanismo / DINAMIA'CETIUL, Escola de Tecnologias e Arquitetura, Edifício ISCTE, Av. das Forças Armadas, 1649-026 Lisboa, Portugal 